\title{
Effectiveness of AutoCAD 3D Software as a Learning Support Tool
}

\author{
http://dx.doi.org/10.3991/ijet.v7i2.1906 \\ Azidah Abu Ziden, Fatariah Zakaria, and Ahmad Nizam Othman \\ Universiti Sains Malaysia, Penang, Malaysia
}

\begin{abstract}
The aim of this study is to test the effectiveness of AutoCAD 3D software in learning of Engineering Drawing to enhance students understanding. Data were collected from a sample of students from a secondary school in Sungai Petani, Kedah. The quasi experimental design was used to find the effectiveness of the software in improving student's achievement. The result from this study shows excellent increases in student achievement after using this software. These indicate the software can help school student visualization capability. This study suggests that teachers, school administrators and government to consider this software as learning tool in Malaysia school.
\end{abstract}

Index Terms-AutoCAD 3D, Engineering Drawing, teaching, learning, visualization.

\section{INTRODUCTION}

The current education system is undergoing very rapid changes. In the past few years, teaching with computeraided software has been used very extensively in teaching and learning. Rapid developments in multimedia technology leads a big change in education nowadays transform the way to get information.

Technical and Vocational Education are not left out in tremendous responsibility to implement the increased use of computer-aided teaching and learning (CATL) software in line with developments in ICT. The use of computers becomes increasingly important in generating and developing ideas and creativity of teachers in the teaching and learning process. Teacher skills in adapting CATL as a teaching tool are considered important in expanding the level of mastery and use of the Technical and Vocational Education. The use of CATL software in teaching and learning means using computers in a planned and appropriate manner to improve efficiency and effectiveness of teaching and learning. Engineering drawing subject need to be assisted by using computer-aided tool to help improve students' visualization.

A number of studies have been conducted to explore the effectiveness of computer aided software in engineering drawing. Computer-aided learning (CAL) research studies have usually evaluated CAL as a supplement or alternative to traditional learning resources, and have invariably shown CAL to be as effective as or superior to the alternative resources [1]. Educational researchers have shown that teaching to develop this type of cognitive activity, rather than teaching to deliver knowledge, fosters competence [2].

\section{A. Engineering Drawing}

Engineering drawing (ED) is a technical subject which is required to learn by engineering or technical students at form four and five. In this subject, students should reflect the objects before they can disclose the views of the drawings on paper. Many students have problems to imagine or see the structure of the object from different viewpoints. In mental visualization topic such as Orthographic Drawing, students learn to mentally rotate an image to reflect the actual form of the main view of Orthographic which are top view, front view and side view [3].

Students need to apply all the understanding and knowledge they have acquired to a drawing or geometry form in ED subject [4]. The researcher further stressed that students can solve their problems in the subject, with the support of visualization techniques. This is in line with other researchers that said most students find it difficult to apply the concepts and theories to solve problems in ED subject due to weaknesses in visualization skills [5][6]. The ability of visualization is an important cognitive skill in engineering, especially in the ED because it requires the ability of an individual's mind to see an object or symbol and think in two or three dimensions [7]. This view is supported by several studies which revealed that the success of an individual in the ED visualization depends on the ability of the individual, but the individual will be very difficult to solve ED if their visualization capabilities are weak [8][9][10].

Visualization skill is an essential ingredient for student understanding in engineering education. Visualization is the mental manipulation of the object and parts of the object in two dimensions and three dimensions [11]. Some studies have reported that students often face problems in orthographic drawings because of the weakness to form a good visualization [12]. Visualization refers to the ability of the mind to see an object or symbol and think in two or three dimensions in the mind of an individual [12].

\section{B. Computer-aided Teaching and Learning (CATL)}

The development of computer-aided teaching and learning (CATL) software in education began in the 1950s and the United States was the first country to have developed CATL programme.

Project that has been developed among CATL is Programmed Logic for Automatic Teaching Operation (PLATO) by the University of Illinois in 1960 [13]. PLATO is using text and graphic elements as well as the first environment that use computers in teaching and learning. While in 1972, Time-shared Interactive Computer Controlled Instructional Television (TICCIT) project introduced the use of minicomputers for computer-aided learning and teaching [14]. The TICCIT project introduces the concept of student-centered teaching [15]. CATL 
should apply theories of learning that can help students to think and implement an active learning process [16]. CATL should also assist students in explore, solve problems and learn a concept effectively. All this can only be achieved if the development of a CATL based on an appropriate theory as the theory of constructivism. CATL should also be applied to help students to master concepts in a subject such as engineering drawing.

\section{Methodology}

Quasi experimental research methodology was applied. Form 5 technical students were selected and divided into two levels of high-level and middle-level group of students. Both groups of students have occupied the pre-test using 2D software in Orthographic projection and the class was handled by two teachers who teach Engineering Drawing. Pre-test was used 2D software, while post-test was used AutoCAD software.

Both pre and post questions are different but have the same level of difficulty. Time allocated to complete the questionnaire was two hours. Results from both studies were analyzed to obtain the achievement scores. Sample of this research were Form 5 students from technical stream in Sekolah Menengah Teknik Sungai Petani 1 (SMTSP1). High and medium level student were categorized based on their Engineering Drawings achievement in the last mid-term exam. Students from the class 5T1 were pooled in a high-level group and students from class 5T4 were in a low-level group. Total of the sample from both classes were 38 people.

Research instrument that was used is Orthographic drawing test. The questions have been validated by two experienced teachers with ten years teaching experience and one of the teachers is an examiner of Malaysia Education Certificate exam for Engineering Drawings subject. The instrument was consisting of five block pictures that have been categorized into easy, moderate and difficult level. Improvements have been done after receiving suggestions and comments from evaluators. In answering this question, respondent should draw the front, side and plan view on drawings paper that have been prepared.

\section{A. Data collection procedures}

Students were given instruction on steps to be followed when conducting pre-test. After that, students from both groups occupied pre-test where each student draws three Orthographic projection views in a paper prepared with the assistance of 2D software. The test was conducted within 2 hours. Students received treatment by using AutoCAD 3D software after the pretest was completed. Then, they were occupied the post test questions related to topics that have been studied for 2 hours. Data collected were analyzed using SPSS software version 14 for the mean scores for pre and post test. A t-test analysis was performed to ascertain whether the AutoCAD 3D was effective in assist student to improve their achievement in Orthographic Drawing subject.

\section{RESULTS}

The highest achievement scores in the pre-test was $44 / 50$, while the lowest was $30 / 50$. For post test, the highest achievement was 50/50 while the lowest score was 33/50. Refer to Table 1, the mean post-test achievement scores (43.25) has increased by 6.35 from the achievement of pre-test mean score (36.90).

Mean scores indicated the improvement of pre-and post test achievement in Orthographic Drawing results among students in the high level group.

TABLE I.

RESULT OF HIGH LEVEL GROUP OF STUDENT ACHIEVEMENT IN PRE AND POST TEST

\begin{tabular}{|l|l|l|l|l|}
\hline \multicolumn{1}{|c|}{ Group } & \multicolumn{1}{c|}{$\boldsymbol{N}$} & \multicolumn{1}{c|}{ Minimum } & \multicolumn{1}{c|}{ Maximum } & \multicolumn{1}{c|}{ Mean } \\
\hline High level pre & 20 & 30 & 44 & 36.90 \\
\hline High level post & 20 & 33 & 50 & 43.25 \\
\hline
\end{tabular}

Result obtained from t-test analysis showed that the mean score of student's achievement using 2D software and using AutoCAD 3D was significantly different at $\mathrm{P}<0.05$. It was proved that the use of $3 \mathrm{D}$ AutoCAD software provides a positive impact on students.

TABLE II.

T-TEST RESULT OF HIGH LEVEL GROUP OF STUDENT ACHIEVEMENT IN PRE AND POST TEST

\begin{tabular}{|l|c|c|l|l|}
\hline \multicolumn{1}{|c|}{ Group } & $\boldsymbol{t}$ & $\boldsymbol{d f}$ & \multicolumn{1}{c|}{ Sig. (2-tailed) } & \multicolumn{1}{c|}{ Mean } \\
\hline High level pre & 46.843 & 19 & .000 & 36.90 \\
\hline High level post & 38.175 & 19 & .000 & 43.25 \\
\hline
\end{tabular}

There were18 respondents from middle level group were involved in pre and post test. Results of the pre test and post test were obtained by students in this group are shown in Table 3. Improvement in their results showed that the use of AutoCAD software in Orthographic drawings subject had a positive impact on students' understanding.

TABLE III.

RESULT OF MEDIUM LEVEL GROUP OF STUDENT ACHIEVEMENT IN PRE AND POST TEST

\begin{tabular}{|l|l|l|l|l|}
\hline \multicolumn{1}{|c|}{ Group } & $\boldsymbol{N}$ & Minimum & \multicolumn{1}{c|}{ Maximum } & Mean \\
\hline Medium level pre & 18 & 26 & 40 & 34.11 \\
\hline Medium level post & 18 & 30 & 49 & 39.78 \\
\hline
\end{tabular}

The highest result in pre test was 40/50 whereas the lowest was 26/50. After using AutoCAD 3D the highest result was increased to $49 / 50$ and the lowest was 30/50. Mean achievement scores after using AutoCAD 3D shows an increase of 5.67 compared with achievement scores before using the software.

TABLE IV.

T-TEST RESULT OF MEDIUM LEVEL GROUP OF STUDENT ACHIEVEMENT IN PRE AND POST TEST

\begin{tabular}{|l|c|l|l|l|}
\hline \multicolumn{1}{|c|}{ Group } & \multicolumn{1}{c|}{$\boldsymbol{d}$} & $\boldsymbol{d} \boldsymbol{f}$ & \multicolumn{1}{c|}{ Sig. (2-tailed) } & \multicolumn{1}{c|}{ Mean } \\
\hline High level pre & 46.843 & 19 & .000 & 36.90 \\
\hline High level post & 38.175 & 19 & .000 & 43.25 \\
\hline
\end{tabular}

As students in high-level group, the achievement scores of students from medium-level group also showed a significant difference at significant level $\mathrm{P}<0.05$ between pre test and post test. 


\section{DISCUSSION}

This study focused on whether teaching using 3D AutoCAD software could serve as an effective medium for teaching and learning. To carry this study the researcher has built a 3D object using an AutoCAD software 2009 version. Every surface in this object has been colored according to the type of view (top view, side view and plan view) so that students easily identify each view to be drawn. Students were divided into two groups namely the high-level group and the moderate level group which both of the group should go through pre-test and post-test. Data from the findings were analyzed using SPSS software to obtain the mean scores of each group and t-test analysis was conducted to determine whether student achievement before and after using 3D AutoCAD software is significant or not.

Findings from this study indicate that the mean score of student's achievement for Orthographic drawings using AutoCAD 3D software is significantly higher than the mean score of student's achievement using 2D software. Students with higher cognitive processes are able to describe the image rotation easier and its help them to understand the concepts easily and effectively. Complex shapes that difficult to be visualized by the student will be easier because the rotation of $3 \mathrm{D}$ objects is capable of overcoming the problem.

Engineering drawing requires high visualization to imagine objects to be drawn. According to previous research, students need to apply all the understanding and knowledge they have acquired in a painting or geometry in engineering drawing subjects [4]. The researcher stressed that students can solve problems in the ED with the visualization support. This view is in line some researchers who said that most students find it difficult to apply the concepts and theories to solve the problem in ED due to weaknesses in the skills of visualization [5][6]. The ability of visualization is an important cognitive skill in engineering, especially in the ED because the subject requires the mind ability to see an object or symbol and think in two or three dimensions [7]. This opinion is supported by several studies which showed that the success of an individual in the ED depends on the visualization capabilities of the individual, but the individual will be very difficult to solve ED if their visualization capabilities is weak [8][9][10].

These findings showed that there was a positive increase in the use of 3D software in the teaching of Orthographic Drawing. Increases in the achievement scores prove that this software could provide a positive impact on students even though the students included in group with modest cognitive skills. Alessi and Trollips also agreed that the initial performance of novice students is higher when the level of simulation perfection is moderate [17]. They also revealed that simulation at the high level of perfection will put pressure on novice students as well as a barrier to learning. The 3D AutoCAD software is more realistic than $2 \mathrm{D}$ software, but the tendency of visual perception of the elements and stands out as the projection and the line [18].

Principle of coherent was held to enable students to learn more about the absence of elements extraneous more actively facilitate the process of cognitive support for learning [19]. This software can improve student learning to a better understanding. A moderate cognitive level is not an obstacle to the success of teaching and learning as it has been proved in this study that the important element in the success of learning depends on the way of the teacher performance. In other words the software is built to be compatible with the cognitive level of students.

This study has found that moderate levels of groups of students perform better when teachers apply the 3D software in their learning instead of 2D software that has been adopted before. This is proved by the findings obtained which showed a positive performance after treatment using 3D AutoCAD software. This study also showed that the use of 3D software give a positive impact on learning even for moderate level group. This is because students from these groups showed remarkable as studies performed on high-level group. Even they have a moderate cognitive level but with this software, pattern of student performance can be improved to a better level. This explains that a moderate level of cognitive not a reason to say they are weak in the ED, but approaches the subject of teaching methods should be varied. Learning using 3D software is able to help students with low levels of visualization to perform well in ED subjects. Findings show there is a significant relation toward learning using 3D AutoCAD software.

\section{CONCLUSION}

Increase of performance of high and medium level students group gave a positive impact on the study. Effective use of this software proved to be helpful based on the data obtained. Thus, the expanded use of this software is proposed to all schools that teach ED to ease students to learn the subject as well as attract them to study.

\section{REFERENCES}

[1] D.R. Keane, G.R. Norman, J. Vickers. The inadequacy of recent research on computer-assisted instruction. Acad Med 1991;66:444-8.Alessi, S.M \& Trollip, S.R (1991). Computer Based Instruction: Method and Development. Prentice Hall.

[2] R. Glaser, The maturing of the relationship between the science of learning and cognition and educational practice. Learning and Instruction, (1991), pp. 129-144. http://dx.doi.org/10.1016/09594752(91)90023-2

[3] H.K. Pillay. Cognitive load and mental rotation: structuring orthographic projection for learning and problem solving. Instructional Science, (1994), 22, 91-113. http://dx.doi.org/10.1007/BF $\underline{00892159}$

[4] Hatta Ismail (2001). Kefahaman Instrumental dan Kefahaman Relasional Pengajaran Dalam Topik Lukisan Ortografik dan Pandangan Keratan. Universiti Teknologi Malaysia.

[5] E. D. Santos, Yee, L. Cheng, \& J. R. D. Petreche. An On-line Interactive Tutorial on Projective Geometry. Proceeding of 8th International Conference On Engineering Computer Graphics and Descriptive Geometry on 31 July -3 August 1998. USA:ICECGDG.

[6] J.S. Kuang, and W.C. Thomas. A Multimedia-based Approach to Teaching Engineering Drawing. Proceeding of The Second Teaching and Learning Symposium Hong Kong. 17 Mei 2004. Hong Kong: Senate Committee on Teaching and Learning Quality, and Centre for Enhanced Learning and Teaching, HKUST.

[7] Jayasree Jayadevan. Keberkesanan Grafik Komputer dan Latihan Kemahiran Spatial Ke Atas Pelajar Lukisan Kejuruteraan-Satu Kajian Kes. Universiti Teknologi Malaysia: Master Thesis. 2003.

[8] S. E. Wiley. Computer graphics and the development of visual perception in engineering graphics curricula. EDG Journal, 54(2), 1990. 39-43.

[9] G. Bertoline, E. Wiebe, C. Miller and J. Mohler. Technical Graphics Communication (2 ${ }^{\text {nd }}$ edn), 1997 (Irwin McGraw-Hill Inc.: Chicago). 


\section{SHORT PAPER}

\section{EFFECTIVENESS OF AUTOCAD 3D SOFTWARE AS A LEARNING SUPPORT TOOL}

[10] S. A. Sorby, \& B. J. Baartmans. "The Development and Assessment of a Course for Enhancing the 3-D Visualization Skills of First Year Engineering Students”, Journal of Engineering Education, Vol. 89, No. 3, 2000, pp.30 -307.

[11] S. Olkun. Making Connections: Improving Spatial Abilities with Engineering Activities (Electronic version). International Journal of Mathematics Teaching and Learning, 2003.

[12] M.F. Lee \& Widad Othman. Designing a Visualization Based Learning Approach for Learning Engineering Drawing (2003). Retrieved from http://eprints.oum.edu.my/62/1/e-engineering dra wing.pdf

[13] M.I. Alpert, W.T. Anderson Jr. Optimal Heterophily and Communication Effectiveness: Some Empirical Findings. Journal of Communication 1970, 23(13), pages 328-343

[14] M. Merrill, E. Schneider, \& K. Fletcher, TICCIT. Englewood Cliffs, NJ: Educational Technology Publications, 1980.

[15] F.T. Wydra. Learner controlled instruction (Englewood Cliffs, NJ: Educational Technology Publications cited in Doherty, P.B. 1998. "Learner Control in Asynchronous Learning Environments" ALN Magazine 2 (2).

[16] Rio Sumarni Shariffudin. "The Use of Computer in Malaysia Schools and The Effectiveness of Computer-assisted Instruction for The Learning of Some Science Concepts.” PhD Thesis, Universiti Teknologi Malaysia, 1996.

[17] S. Alessi \& S. R. Trollip. Multimedia for learning. Methods and development. Boston: Allyn and Bacon, 2001.

[18] I. Biederman. Recognition-by-Components: A Theory of Human Image Understanding. Phsycological Review, 94, 1987, 115-147. http://dx.doi.org/10.1037/0033-295X.94.2.115

[19] R. E. Mayer. Multimedia learning. New York: Cambridge University Press, 2001.

\section{AUTHORS}

Azidah Abu Ziden is a lecturer of School of Educational Studies, Universiti Sains Malaysia. (e-mail: azidahziden@gmail.com)

Fatariah Zakaria is a research officer of mobile@usm, Universiti Sains Malaysia. (fata.syahid@gmail.com).

Ahmad Nizam Othman is a master student in School of Educational Studies, Universiti Sains Malaysia.

Received 21 January 2012. Published as resubmitted by the authors 27 May 2012. 